\title{
Alfabetização e letramento: de como se aprende a como se ensina
}

\author{
Kadine Saraiva de CARVALHO (D) \\ Universidade de Santa Cruz do Sul (UNISC)
}

\section{RESUMO}

A professora Magda Soares discute as concepções de alfabetização e letramento, afirmando que a aprendizagem do sistema de escrita deve ocorrer contemporaneamente à aprendizagem dos usos sociais desse sistema, o que a pesquisadora chama de "alfaletrar". Nesse mesmo sentido, Soares aborda a questão das teorias e práticas voltadas à alfabetização, explica que não deve haver um único método a ser seguido e critica o Plano Nacional de Alfabetização (PNA), que recomenda, especificamente, o método fônico. Magda Soares aborda a teoria da Psicogênese da língua escrita, desenvolvida por Ferreiro e Teberosky (1986), apresentando evidências de todos os estágios que compõem essa teoria através de exemplos produzidos por alunos em processo de alfabetização. A professora evidencia em sua fala a tentativa de articulação entre a Linguística e a Educação.

EDITADO POR

Raquel Freitag

AVALIADO POR Eliane Vitorino de Moura Oliveira

DATAS

Recebido: 07/08/2020 Aceito: 16/08/2020 Publicado: 31/08/2020

COMO CITAR

Carvalho, K. S. (2020). Alfabetização e letramento: de como se aprende a como se ensina. Revista da Abralin, v. 19,

n. 2, p. 1-5, 2020.

\section{ABSTRACT}

Professor Magda Soares discusses the concepts of reading acquisition and social literacy, stating that the learning of the writing system must occur simultaneously with the learning of the social uses of that system, what the researcher calls "alfaletrar". In the same sense, Soares addresses the issue of theories and practices aimed at reading acquisition, she explains that there should not be a single method to be followed and criticizes the National Literacy Plan (PNA), which specifically recommends the phonic method. Magda Soares addresses the theory of Psychogenesis of written language, developed by Ferreiro and Teberosky (1986), presenting evidence of all stages that make up this theory through examples produced by students in the process of reading acquisition. The teacher evidences in her speech the attempt to articulate Linguistics and Education. 


\section{REVISTA DA ABRALIN}

PALAVRAS-CHAVE

Alfabetização. Letramento. Métodos.

\section{KEYWORDS}

Reading acquisition. Social literacy. Methods.

A palestra da professora Magda Soares ocorreu no dia 31 de julho de 2020, no último dia da série de palestras Abralin ao vivo, que teve início em maio de 2020, numa promoção da Associação Brasileira de Linguística (ABRALIN). A fala da palestrante teve aproximadamente 5 mil visualizações durante a transmissão e chegou a mais de 45 mil visualizações após uma semana. Magda Becker Soares é professora emérita da Universidade Federal de Minas Gerais, onde também cursou a graduação em Letras Neolatinas (1953) e o doutorado em Didática (1962). Pesquisadora do Centro de Alfabetização, Leitura e Escrita (Ceale), é também presidente de honra da Associação Brasileira de Alfabetização (ABAlf).

Soares inicia a apresentação expressando sua preocupação com o fracasso na alfabetização e letramento no Brasil, o qual é indicado pelas avaliações externas (estaduais, nacionais e internacionais). A pesquisadora cita alguns dados alarmantes, como o de que a Avaliação Nacional de Alfabetização (ANA), realizada em 2016, mostrou que apenas metade das crianças tem proficiência em leitura no final do terceiro ano. Também chama a atenção para as escassas notas máximas do Exame Nacional do Ensino Médio (ENEM) e para a posição do Brasil no Programa Internacional de Avaliação de Estudantes (PISA), ocupando o $57^{\circ}$ lugar em leitura. Esses resultados apontam para o fracasso em leitura em todos os níveis de escolarização, o que, segundo Soares, é gerado no início do processo de aprendizagem da língua escrita, quando são formados os alicerces do leitor e produtor de textos.

Segundo a professora, esse fracasso concentra-se em escolas públicas, que atendem cerca de 20 milhões de crianças da educação infantil e anos iniciais do Ensino Fundamental. A dimensão do problema educacional soma-se ao status socioeconômico (SES) dessas crianças, que são duplamente prejudicadas já na construção da base de sua formação. Portanto, Soares acredita que é preciso haver persistência de denunciar o fracasso, pois a alfabetização e o letramento são a solução de muitos problemas. A pesquisadora enfatiza a conjunção aditiva "e" entre alfabetização e letramento, explicando que há uma relação de soma entre os dois processos e que devem acontecer simultaneamente desde a educação infantil e durante todo o processo de aprendizagem da língua escrita.

Soares apresenta um esquema em camadas que se sobrepõem. A primeira delas diz respeito a "aprender o sistema de escrita alfabética", que fornece insumos para o desenvolvimento da camada seguinte, "ler e escrever textos", habilidade que já é possível na fase de alfabetização. Ultrapassando essa camada, temos os "usos da escrita", que envolvem o contexto sociocultural, a questão de gêneros textuais e a linguística do texto. A camada mais ampla, que permeia/abrange todas as camadas anteriores, é intitulada "contextos sociais e culturais de usos da escrita", que se refere ao processo de letramento, ou seja, o uso competente da leitura e da escrita em práticas sociais. Essa união entre 


\section{REVISTA DA ABRALIN}

a alfabetização e o letramento é o que a pesquisadora chama que "alfaletrar", com a pretensão de os dois processos serem simultâneos. Nesse contexto, a professora chama a atenção para a escolha de textos, afirmando que é importante que se trabalhe com textos reais, de diferentes gêneros, da mesma forma que é preciso criar uma motivação para a produção de textos. Soares critica o uso de textos elaborados apenas para fins de alfabetização, visão que é confrontada por José Morais em Alfabetizar para a democracia (conf. MORAIS, 2014, p. 61).

Referindo-se ao título da conferência, a pesquisadora chama a atenção para os termos "teorias" e "práticas", que também se somam e interagem. Ambos estão no plural porque não há apenas uma teoria, mas diversas teorias que oferecem fundamentos para os processos de alfabetização e, dessas teorias, surgem muitas práticas. Com base nessas teorias e nas evidências que delas decorrem é que se pode definir como ensinar e quando ensinar, o que implica em métodos de alfabetização, no plural, não apenas um método. Magda Soares deixa claro que é contra a utilização de um único método para a alfabetização.

Nessa perspectiva, a professora critica o Plano Nacional de Alfabetização (PNA), o qual recomenda a utilização do método fônico na alfabetização com a justificativa de ser o único método baseado em evidências científicas. Soares diz que essas evidências vêm do relatório do National Reading Panel, divulgado em 2000, nos Estados Unidos, o qual traz conclusões que não se adequam ao contexto brasileiro, uma vez que são de um sistema de escrita diferente do português: enquanto a língua inglesa tem uma ortografia opaca, a língua portuguesa se aproxima de uma ortografia transparente. Ela afirma que a profundidade ortográfica é um aspecto muito importante a ser considerado quando se discute alfabetização, pois o processo de desenvolvimento linguístico e cognitivo de uma criança inglesa e de uma criança de um sistema de escrita mais transparente, como o português brasileiro, se dá de forma diferente, visto que ela estará aprendendo um objeto de conhecimento mais simples ou mais complexo.

A pesquisadora afirma que outras teorias, que divergem do método fônico, também podem ser consideradas evidências científicas, como a teoria da Psicogênese da língua escrita, baseada no construtivismo, desenvolvida por Ferreiro e Teberosky, em 1986, que traz evidências científicas porque pode ser replicada e comprovada em línguas de ortografias mais transparentes (ex.: espanhol, catalão, italiano e português) com sucesso. Soares explica que, diferentemente do que muitos pensam, construtivismo não é um método, mas uma teoria do conhecimento, por isso não pode ser comparado com o método fônico. O construtivismo desloca o foco para o aluno, respeitando as peculiaridades do processo de cada criança (SOARES, 2016), tornando impossível a utilização de apenas um método.

A pesquisadora explica que a psicogênese da língua escrita considera o desenvolvimento linguístico e cognitivo da criança ao longo da aprendizagem da escrita, trata-se de uma teoria baseada em estágios pelos quais todas as crianças passam no processo de alfabetização, são eles: icônico; garatuja; escrita com letras; silábico sem valor sonoro; silábico com valor sonoro; silábico-alfabético e ortográfico. Na conferência, a pesquisadora explica todos os estágios, mostrando exemplos de crianças em cada um deles. Soares fala sobre a importância do desenvolvimento da consciência fonológica e da atenção aos traços que compõem as letras para o seu reconhecimento, também comenta 


\section{REVISTA DA ABRALIN}

sobre a relevância de saber a ordem alfabética, considerando o contexto sociocultural, no qual essa ordem é bastante utilizada. Tudo isso para chegar ao objetivo principal: relacionar letras com os fonemas que representam.

A crítica de Soares à utilização unitária do método fônico é, principalmente, porque esse método inicia diretamente com as relações entre letras e fonemas, pulando etapas que a pesquisadora considera importantes e desconsiderando o desenvolvimento de cada criança. É possível perceber na fala da conferencista que a grande questão - ou o problema - não é a utilização do método fônico, mas o descarte de outros métodos. Soares acredita que é preciso deslocar o eixo das discussões dos métodos de ensino (como ensinar) para o processo de aprendizagem da criança (como se aprende), o que, na verdade, também é uma conclusão dos defensores do método fônico. Se acompanharmos a literatura internacional relacionada à ciência da leitura (ex. DEHAENE, 2012), veremos que a neurociência fornece evidências sobre como a aprendizagem da leitura e escrita acontece no cérebro, trazendo fortes aliados à instrução fônica.

Ambas as visões focam em compreender o processo de aprendizagem, mas, aparentemente, passam a ser consideradas antagônicas em algum momento. A tensão entre essas abordagens resulta nas famosas "guerras de leitura" (reading wars) (SEIDENBERG, 2013), também mencionadas por Magda Soares. Na França, foi realizada uma Assembleia de Consenso (Conférence de consensus: lire, comprendre, apprendre), primeiro em 2003 e depois em 2016, organizada por Jean Emile Gombert. Nessa assembleia, foram discutidas questões relacionadas à alfabetização com o objetivo de chegar a um consenso entre as diferentes visões/teorias/métodos e, a partir disso, elaborar recomendações. A Assembleia é composta por professores, conselheiros pedagógicos, equipes de inspeção, chefes de instituições, formadores e também por pais de alunos. Essa iniciativa parece muito válida também no contexto brasileiro.

Ao abordar seu lugar de fala, Soares conta que ora dizem que ela é da área da Educação, ora dizem que é da Linguística, mas que seu objetivo é articular essas duas áreas de formação. Sua trajetória deixa traços dessa intenção, visto que atuou, primeiramente, em escolas públicas, mais tarde dedicou-se à formação de professores na universidade, desenvolvendo pesquisas relacionadas à alfabetização e, depois de aposentar-se, inseriu-se novamente nas escolas públicas com projetos para compreender o que está acontecendo no ambiente escolar. Na fala da pesquisadora, é possível perceber um viés prático, uma vez que ela traz ideias de como o professor pode ajudar a criança a identificar os fonemas de forma lúdica e como deve-se trabalhar para desenvolver a consciência grafofonêmica, unindo as teorias às possíveis práticas. 


\section{REVISTA DA ABRALIN}

REFERÊNCIAS

ALFABETIZAÇÃO e letramento: teorias e práticas. Conferência apresentada por Magda Becker Soares [s.l., s.n.], 2020. 1 vídeo (2h 26min 15s). Publicado pelo canal da Associação Brasileira de Linguística. Disponível em: https://www.youtube.com/watch?v=UnkEuHpxJPs . Acesso em: 26 ago 2020.

DEHAENE, Stanislas. Os neurônios da leitura: como a ciência explica nossa capacidade de ler. Tradução de Leonor Scliar-Cabral. Porto Alegre: Penso, 2012.

MORAIS, José. Alfabetizar para a democracia. Porto Alegre: Penso, 2014.

SEIDENBERG, Mark S. The science of reading and its educational implications. Language learning and development, v. 9, n. 4, p. 331-360, 2013. DOI: $10.1080 / 15475441.2013 .812017$

SOARES, Magda. Alfabetização: a questão dos métodos. São Paulo: Contexto, 2016. 